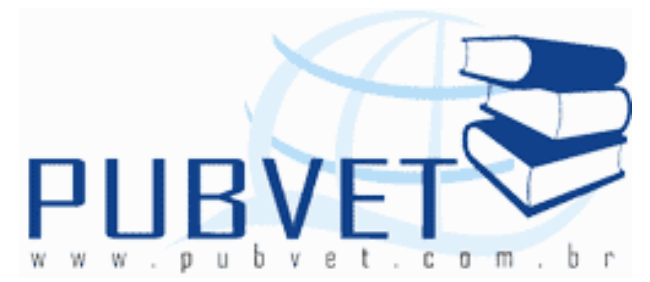

PUBVET, Publicações em Medicina Veterinária e Zootecnia.

\title{
Distribuição percentual do rendimento da carcaça de ovino Santa Inês
}

Adelmo Ferreira de Santana1, Silvana Vollono², Lívia Paola Silva Resende², Adriano Leão Silva Caetano ${ }^{1}$, Gessica Ariane de Melo Cruz $^{3}$

${ }^{1}$ Médico Veterinário, Professor do Departamento de Produção Animal da Escola de Medicina Veterinária - UFBA.

${ }^{2}$ Estudante de graduação da Escola de Medicina Veterinária - UFBA

${ }^{3}$ Médica Veterinária

\section{Resumo}

Este trabalho avaliou o rendimento percentual dos componentes da carcaça de ovino Santa Inês, realizado na Fazenda Experimental de Entre Rios, levando em consideração abate com idade média de 5 meses. Foi realizado o acompanhamento das matrizes gestantes, controle sanitário e parto de 14 cordeiros. Durante os meses que antecederam o abate foi feito o manejo dos cordeiros, coleta de fezes para o exame de OPG de verminoses e eimeriose. Foi realizada a vacinação, vermifugação e realização de novo exame OPG para verificar a eficácia do tratamento antiparasitário. Na data do abate os cordeiros foram pesados e em seguida abatidos e levados à câmara frigorífica $\left(-4^{\circ} \mathrm{C}\right.$ a $1^{\circ} \mathrm{C}$ ) onde permaneceram por 12 horas foram pesados, calculando-se a perda por resfriamento. Feitas as análises estatísticas, foram avaliados neste experimento a composição percentual do rendimento dos cortes de carcaça com osso e desossadas feitas com cortes padronizados.

Palavras-chave: Santa Inês, rendimento, carcaça, desossadas, cortes. 
SANTANA, A.F. et al. Distribuição percentual do rendimento da carcaça de ovino Santa Inês.

PUBVET, Londrina, V. 5, N. 33, Ed. 180, Art. 1216, 2011.

\title{
Percentile distribution of the income of the carcass of ovino Santa Inês
}

\begin{abstract}
The study value the percentile income of the components of the carcass of ovino Saint Ines, carried through in the Experimental Farm of Between Rivers, leading in consideration abates with age average of 5 months. The accompaniment of the gestantes matrices was carried through, has controlled bathroom and childbirth of 14 lambs. During the months that had preceded it abates it the handling was made of the lambs, excrement collection for the examination of OPG of verminoses and eimeriose. It was carried through the vaccination and vermifugação and accomplishment of new examination OPG to verify the effectiveness of the antiparasitic treatment. In the date of it it abates the lambs had been weighed and after that abated and led to the refrigerating chamber $\left(-4^{\circ} \mathrm{C}-1^{\circ} \mathrm{C}\right)$ where they had remained by 12 hours they had been weighed, calculating it loss for cooling. Made the statistical analyses, had been evaluated in this experiment the percentile composition of the income of the boned cuts of carcass with bone and made with standardized cuts.
\end{abstract}

Keywords: Saint Ines, income, carcass, boned, cuts.

\section{Introdução}

No semi-árido, a criação de ovinos deslanados, com o intuito de produção de carne, surge como uma alternativa sócio-econômica para a Região Nordeste, que possuem altas temperaturas ambientais e ausência de lã na pele dos animais nordestinos são indicadores da grande diferença do rendimento da carcaça (ZAPATA et al., 2001). Atualmente, essa atividade vem sofrendo transformações no tocante à sua eficiência e produtividade, principalmente em razão da globalização do mercado (BARROS e VASCONCELOS, 1998). Atendendo as atuais exigências dos consumidores, 
SANTANA, A.F. et al. Distribuição percentual do rendimento da carcaça de ovino Santa Inês. PUBVET, Londrina, V. 5, N. 33, Ed. 180, Art. 1216, 2011.

estudos estão se direcionando para o aumento da massa muscular nas carcaças ovinas (SAÑUDO et al.,1998; TAHIR et al.,1994).

O ovino da raça Santa Inês foi escolhido por melhor adaptar-se ao clima do nordeste brasileiro. Várias estratégias têm sido utilizadas para conseguir atender a procura dos consumidores por uma carne saudável, dentre elas a escolha da raça (MONTEIRO e SHIMOKOMAKI, 1999). A proporção de cada parte da carcaça bem como a sua conformação depende do tipo racial (PÁLSSON, 1959).

Ovinos destinados ao abate para produção de carne necessitam a determinação idade ideal para serem abatidos, o que permitirá maior produtividade e o encontro das exigências dos consumidores.

Os distintos cortes que compõem a carcaça possuem diferentes valores econômicos e a produção das mesmas constitui um importante índice para avaliação da qualidade comercial da carcaça (HUIDOBRO e CAÑEQUE, 1993). Sabendo-se que a qualidade da carcaça está diretamente relacionada com a genética e o fator nutricional oferecido na alimentação animal. Animais do nordeste brasileiro destacam-se pela rusticidade sendo este um fator que faz estes animais obterem bom desempenho em seu desenvolvimento (SANTANA, 1996).

Este trabalho teve como objetivo avaliar as percentagens médias do rendimento de cada corte da carcaça do ovino Santa Inês e suas proporções percentuais da carcaça com osso e desossada de cordeiros abatidos aos 5 meses de idade em relação ao sexo do animal.

\section{Material e Métodos}

Este trabalho foi realizado na Fazenda Experimental de Entre Rios da Escola de Medicina Veterinária da Universidade Federal da Bahia (UFBA), localizada no município de Entre Rios, Bahia, Brasil. Localizado a uma latitude

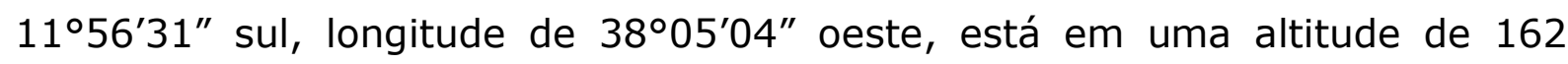
metros, possui clima úmido com temperatura média de $24^{\circ} \mathrm{C}$. 
SANTANA, A.F. et al. Distribuição percentual do rendimento da carcaça de ovino Santa Inês. PUBVET, Londrina, V. 5, N. 33, Ed. 180, Art. 1216, 2011.

Os animais foram mantidos com alimentação à pasto de braquiária (Brachiaria decubens) e capim pangola (Digitaria decubens) e com suplementação mineral até o abate. Foram selecionados 14 animais Santa Inês, sendo fêmeas e machos, ao nascer e colocados brincos plásticos para seu manejo e identificação posterior. Os animais foram vermifugados, de modo que este aspecto não influenciasse nos resultados. O período experimental foi de 150 dias sendo os cordeiros abatidos com jejum de 12 horas. Foi feita a pesagem antes do abate, abatidos foram submetidos à lavagem gastrintestinal (evisceração), pesados verificando-se assim o peso da carcaça quente, após foi realizado o resfriamento $\left(-1^{\circ} \mathrm{C}\right.$ a $\left.-4^{\circ} \mathrm{C}\right)$ por 12 horas para o cálculo do rendimento verdadeiro e do rendimento comercial. Foi feita a separação regional (cortes) e separação dos componentes teciduais (osso, músculo e gordura) tomando-se o antímero direito separou-se o pescoço (entre a $3^{a}$ e $4^{a}$ vértebra cervical), costela (junto à coluna vertebral) conservando-se todos os ossos), paleta (liberando a escápula da costela), quarto (região sacral) . Foi realizada a pesagem do quinto quarto (vísceras verdes, patas, pulmões com traquéia, fígado, rins, coração e baço). Feita a pesagem dos diferentes cortes comerciais com osso e desossados, foram calculadas sua porcentagens em relação ao peso da carcaça. A separação da carcaça foi realizada seguindo a metodologia descrita por (SILVA e PIRES, 2000).

Os cálculos foram feitos usando-se os dados de: peso da carcaça quente/ peso vivo X 100 (rendimento verdadeiro); peso da carcaça fria / X 100 (rendimento comercial); PCQ-PCF / PCQ X 100 (perda por resfriamento); composição tissular (ossos, músculos, gordura da paleta e quarto); porcentagem dos componentes regionais em relação à carcaça fria; porcentagem do pescoço em relação à carcaça; porcentagem das vísceras em relação ao peso vivo; médias e desvio padrão, porcentagens de cortes de meia carcaça, (SIQUEIRA et al., 2001); peso vivo (PV) antes do jejum ; peso vivo ao abate (PVA) (LANDIM et al., 2007). Cada corte foi pesado, desossado e pesado novamente para a observação da proporção osso/músculo. 
SANTANA, A.F. et al. Distribuição percentual do rendimento da carcaça de ovino Santa Inês. PUBVET, Londrina, V. 5, N. 33, Ed. 180, Art. 1216, 2011.

\section{Resultados e discussão}

A média percentual da perda por resfriamento ficou em torno de $3 \%$, o rendimento comercial em torno de $48 \%$ e o rendimento verdadeiro em torno de $49 \%$ do peso total da carcaça. Ovinos machos foram analisados em conjunto com as fêmeas. A análise foi feita usando-se a média e o desvio padrão, com um nível de significância $(P<0,05)$ pelo teste Pdiff .

Observou que a proporção percentual do rendimento dos diferentes cortes da carcaça com osso, no qual verifica-se a maior média percentual é dada pelo corte do pernil (35,50\%), seguida pelo $1 / 4$ dianteiro $(23,60 \%)$, costela $(16 \%)$, pescoço $(9,40 \%)$, costilhar $(9 \%)$ e lombo $(6,10 \%)$.

Verificou que a maior média percentual do rendimento da carcaça desossada é encontrada no pernil $(25,60 \%)$, seguida de $1 / 4$ dianteiro $(15,70 \%)$, costela $(10,40 \%)$, pescoço $(5,60 \%)$, costilhar $(4,60 \%)$ e lombo $(3,60 \%)$.

Verificam-se os parâmetros das equações de predição da porcentagem de músculo e osso em função da proporção dos mesmos nos diferentes cortes da carcaça.

Para os cortes de primeira (pernil e lombo), cortes de segunda ( $1 / 4$ dianteiro e costela) e cortes de terceira (costela descoberta baixos e pescoço) observa-se que ZUNDT et al. (2002) trabalhando com cordeiros machos Santa Inês, abatidos aos $30 \mathrm{~kg}$ de peso vivo, obteve rendimentos médios para cortes de primeira, segunda e terceira em relação ao peso vivo de 43,20; 27,30 e $28,20 \%$, respectivamente os valores encontrados situam-se em uma faixa ligeiramente diferente aos valores encontrados no experimento. Os resultados mostraram pequenas diferenças no peso e rendimento dos cortes das carcaças, CAÑEQUE et al. (1989), mostrando assim que essa diferença é desprezível, comparando com o respectivo experimento.

Foi avaliado o rendimento percentual médio da carcaça fria em cortes com osso $(51 \%)$, cortes da carcaça desossada (39\%) e a percentagem de 
SANTANA, A.F. et al. Distribuição percentual do rendimento da carcaça de ovino Santa Inês. PUBVET, Londrina, V. 5, N. 33, Ed. 180, Art. 1216, 2011.

vísceras (10\%). A percentagem de vísceras está abaixo do foi observado por SIQUEIRA et al. (2001) que verificou a percentagem de perdas de peso carcaça. Segundo SIQUEIRA et al. (2001) o conteúdo gastrintestinal sofre oscilações pelos distintos alimentos e períodos de jejum que nem sempre são adotados ou padronizados.

\section{Conclusão}

Nos cortes da carcaça com osso nota-se que a maior média percentual é dada pelo pernil, seguido do $1 / 4$ dianteiro, costela, pescoço, costilhar e lombo. Na carcaça desossada avaliou-se os mesmos níveis de correlações de músculos que na carcaça com osso, diferindo apenas no peso dos ossos encontrados nas diferentes partes da carcaça.

\section{Referências}

BARROS, N. N.; VASCONCELOS, V. R. Produção de Borregos para Abate no Nordeste de Brasil In: CONGRESSO DA SOCIEDADE NORDESTINA DE PRODUÇÃO ANIMAL, 1, 1998. Fortaleza. Anais... Fortaleza: SNPA, 1998. V.1, p. 97-107.

CAÑEQUE, V.; HUILDOBRO, F.R.; DOLZ, J.F. Producción de Carne e Cordero. Madrid. Ministério de Agricultura Pesca y Alimentación, 1989, p.520.

HUIDOBRO, F. R., CAÑEQUE, V. Conformación y Estado de Engrasamiento de La Canal y Proporción de Piezas em Distintos Tipos Comerciales. Investigación Agraria, Producción y Sanidad Animal, v.8, n.3, p. 233-243, 1993

LANDIM, A. V. L., MARIANTE, A. S., MCMANUS, C., GUGEL, R., PAIVA, S. R. Características Quantitativas da Carcaça, Medidas Morfométricas e suas Correlações em Diferentes Genótipos de Ovinos. Ciência Animal Brasileira, v. 8, n. 4, p. 665-676, out/ dez. 2007.

MONTEIRO, E. M., SHIMOKOMAKI, M.. Influência do Genótipo nos Lipídios Totais e na Fração Insaponificável da Carne de Cordeiros. Ciência Rural, Santa Maria, v. 23, n. 3, p. 545-548, 1999.

PÁLSSON, H. Avances em Fisiologia Zootécnica. In: Conformación y Composición Del Cuerpo. Zaragosa: Acribia, 1959. p. 510- 641.

SANTANA, A. F., MARTINS FILHO, R. Desenvolvimento Ponderal em Ovinos Deslanados do Nordeste. Arquivo da Escola de Medicina Veterinária- UFBA, Salvador, v. 8, n. 1, p. 2440, 1995-1996. 
SANTANA, A.F. et al. Distribuição percentual do rendimento da carcaça de ovino Santa Inês.

PUBVET, Londrina, V. 5, N. 33, Ed. 180, Art. 1216, 2011.

SAÑUDO, C., SERRA, I., OLLETA, J. L. . Influence of Weaning on Carcass Quality, Fatty Acid Composition and Meat Quality in Intensive Lamb Production Systems. Animal Science, n.66, p. 175-187, 1998.

SILVA, L. F., PIRES, C. C. Avaliações Quantitativas das Proporções de Osso, Músculo e Gordura da Carcaça em Ovinos. Revista Brasileira de Zootecnia, v. 29, n. 4, p. 1253-1260, 2000.

SIQUEIRA, E. R.; SIMÕES, C.D.; FERNANDES, S. Efeito do Sexo e do Peso do Abate sobre a Produção de Carne de Cordeiro: Morfometria da Carcaça, Pesos dos Cortes, Composição Tecidual e Componentes não Constituintes da Carcaça. Revista Brasileira de Zootecnia, v. 30 , n. 4, p. 1299-1307, 2001.

TAHIR, M. A., AL-JASSIM, A. F., ABDULLA, A. H. H. Influence of Live Weight and Castration on Distribuiton of Meat, fat and Boné in the Carcass of Goats. Small Ruminant Research, v. 14, p. 219-223, 1994.

ZAPATA, J. F. F., SEABRA, L. M. J., NOGUEIRA, C. M., BEZERRA, L. C., BEZERRA, F. J., Características de Carcaça de Pequenos Ruminantes no Nordeste do Brasil. Ciência Animal, v.11, n.2, p. 79-86, 2001a.

ZUNDT,M., MACEDO, F. A. F., MARTINS, E. N. Desempenho de Cordeiros Alimentados com Diferentes Níveis Protéicos. Revista Brasileira de Zootecnia, v. 31, n. 3, p. 1307-1314, 2002. 